\title{
Recruitment, Development, and Retention of Dental Faculty in a Changing Environment
}

\author{
Vanchit John, D.D.S., M.S.D.; Maria Papageorge, D.M.D., M.S.; Leila Jahangiri, \\ D.M.D., M.M.Sc.; Michelle Wheater, Ph.D.; David Cappelli, D.M.D., M.P.H., Ph.D.; \\ Robert Frazer, D.D.S.; Woosung Sohn, D.D.S., Ph.D., Dr.P.H.
}

Abstract: The scarcity of full-time clinical faculty members in dental schools across the country is a major crisis confronting dentistry. Dental schools are experiencing critical faculty shortages and are struggling to maintain appropriate faculty to student ratios. The adage of "doing more with less" applies, in many ways, to dental schools and their mission of educating future dentists. Solutions to the problem have included plans to recruit, develop, and mentor faculty members. However, progress has been slow. Dental schools have created incentive programs to help with faculty shortages and develop future educators in dentistry. This requires commitment and resources and will take years before these efforts and their impact can be assessed. Creative solutions need to be developed both nationally and locally to reverse the trend more rapidly.

Dr. John is Chairman, Department of Periodontics and Allied Dental Programs, School of Dentistry, Indiana University; Dr. Papageorge is Associate Dean for Hospital Affairs and Chair, Department of Oral and Maxillofacial Surgery, School of Dental Medicine, Tufts University; Dr. Jahangiri is Chair, Department of Prosthodontics, College of Dentistry, New York University; Dr. Wheater is Director of Research, School of Dentistry, University of Detroit Mercy; Dr. Cappelli is Interim Chair, Department of Community Dentistry, Dental School, University of Texas Health Science Center at San Antonio; Dr. Frazer is Associate Professor, College of Dentistry, University of Kentucky; and Dr. Sohn is Associate Professor, School of Dentistry, University of Michigan. Direct correspondence and requests for reprints to Dr. Vanchit John, Department of Periodontics and Allied Dental Programs, School of Dentistry, Indiana University, 1121 West Michigan Street, Indianapolis, IN 46202; 317-274-5124 phone; 317-274-1363 fax; vjohn@iupui.edu.

Keywords: academic careers, mentoring, dental faculty, faculty development, faculty recruitment, faculty retention

Submitted for publication 2/22/10; accepted 7/16/10

$\mathrm{T}$ The scarcity of full-time clinical faculty members has been documented and discussed in the literature for several years. ${ }^{1-3}$ However, it continues to be a major issue in dental schools. Currently, clinical faculty shortages could be characterized as the most critical challenge confronting dentistry. This challenge could worsen as there are plans to open several new dental schools. The purpose of this article is to shed light on this topic and to offer some options that schools can consider to address the situation.

Reports published over the past years attest that the faculty shortage faced by dental schools is a real one and that the need for more faculty members will not be met in the short term. ${ }^{1-3}$ Traditionally, three tracks are offered for faculty members: the full-time clinician (usually non-tenure-track), the clinician- scholar (tenure-track with teaching, research, and service responsibilities), and the full-time research track (tenure-track with research and graduate education as the main focus). ${ }^{4,5}$ In 2005, dental schools reported 417 vacant faculty positions nationally, a significant increase from previously reported data in 1993. Of the 417 vacancies, 374 were full-time, ${ }^{6}$ indicating that the greatest challenge confronting schools was to attract and keep full-time faculty. In 2007, the number of vacant positions reported was 369 with an average of almost seven vacant positions at each dental school. ${ }^{7}$ Restorative dentistry, in particular, has consistently faced the highest number of vacant positions between 2003 and 2007. ${ }^{6,7}$ Other areas of unfilled, non-clinical positions include research, basic science, administration, and, to a much lesser degree, behavioral science and allied dental health positions. 
If the current retirement trends continue, researchers estimate that the retirement of faculty members age sixty and over will likely produce 900 academic vacancies by the next decade, ${ }^{8}$ further worsening the situation.

\section{Appraisal of the Current Situation}

Haden et al. presented data in 2008 regarding the quality of dental faculty work-life. ${ }^{9}$ In general, dental faculty members seemed to enjoy the roles they played in teaching students and derived significant satisfaction from being associated with dental schools. However, there was career dissatisfaction among tenured associate professors. In spite of the positive information reported in this data, informal discussions with colleagues at our parent institutions raise several concerns. Most significant is faculty burn-out due to time and workload demands. Due to dwindling resources confronting dental schools, many faculty members have become overwhelmed with teaching, clinical, research, and administrative responsibilities. Guskin and Marcy ${ }^{10}$ reported that when schools/universities try to "muddle through" because of diminishing resources, the quality of teaching and scholarly pursuits are affected. In addition, salaries are reduced to a point at which they are not competitive, leading to many faculty members' leaving academia. In this regard, Trotman et al. ${ }^{11}$ made several recommendations, including the following: having school administrators articulate clearly their expectations of faculty members; emphasizing that teaching matters most; establishing a mentoring structure as the cornerstone of faculty development; creating and maintaining an atmosphere of enthusiasm among faculty members, staff, and students; and faculty members' doing their background work to make sure that the position and the school/department environment are good for them.

Another area of concern is time. As faculty workloads have increased, fewer and fewer clinical faculty members have time to participate in scholarly activity. This has a negative impact on their prospects for promotion and tenure, thereby also affecting their chances of earning a significant pay increase. The lack of time for scholarly activity has led to an increasing trend in which tenure-track faculty members switch to non-tenure-track positions. Associated outcomes include decreased job security and the inability to feel a sense of accomplishment. Indeed, recent data indicate that 93 percent of part-time clinical faculty members and 62 percent of full-time clinical faculty members failed to publish a single article. ${ }^{12}$ In addition, only 7 percent of part-time faculty members and 11 percent of full-time faculty members have published three or more articles in medical/dental journals during their service as part of the clinical faculty. ${ }^{12}$ All of these factors have led many faculty members to leave their academic careers for other opportunities, usually opting for a full-time dental practice. The most common reasons cited by those leaving academic institutions are as follows: academic demands of the position, leaving academia to enter private practice, completion of a fixed term, retirement, moving from one school to another, death, and other/not reported. ${ }^{13}$

Since many reports have clearly identified a problem, what plans do dental schools and professional organizations like the American Dental Education Association (ADEA) have in place to tackle this issue of faculty shortages? Recently, it was appropriately suggested that we stop talking about the problem and instead begin looking for solutions. ${ }^{14}$ Citing a 1950 American Dental Association Transaction: Annual Report of the Council on Dental Education, which identified twenty-eight dental schools reporting 135 faculty vacancies, Bertolami ${ }^{14}$ writes that the issue of faculty shortage is not new among dental schools. Sources from which dental schools have traditionally drawn their faculty include private practice, other dental schools, graduates from an advanced education program, dental school graduates, and the uniformed services. ${ }^{15}$

The intent of this article is to bring additional attention to the issue of faculty shortages in dental school. However, we are also focusing on the topic of developing faculty from within dental schools by implementing a plan usually referred to as "Growing Our Own." ${ }^{.14}$ For this effort to be successful, dental school administrators must be willing to develop intra-school programs that identify and expose interested dental students and specialty residents to the idea of teaching as a career option. This is especially important as Chmar et al. ${ }^{15}$ listed the following as among the obstacles cited for a lack of interest in an academic career: limited knowledge about opportunities available and lack of formal mentoring programs. 


\section{Developing Future Educators: Review of Current Models}

Over the years, various initiatives have been developed to address the issue of clinical faculty shortages. Haden et al. ${ }^{3}$ in a survey of dental school deans reported that 91 percent of dental schools had in place either formal or informal programs to prepare, recruit, and retain faculty members. However, in spite of an increased awareness of the problems and many attempts to remedy the situation, the problem of faculty shortages persists. Currently, many of the solutions that are in place or being planned focus on informing and exposing dental students to the option of academics as a career choice, either on a full- or part-time basis. Most students view the end point of dental education as being unidirectionalnamely, a career practicing clinical dentistry. Rupp at al. ${ }^{16}$ reported that, in a survey of 561 students from eleven dental schools, the knowledge level of academic issues was very low. While the private practice of dentistry is without doubt the primary reason students apply to dental schools, it is important to expose students to various career choices including academic dentistry.

In 2005, the Academy for Academic Leadership (AAL) developed the Institute for Teaching and Learning for new and transitional faculty members involved with predoctoral, allied, and postdoctoral dental education. The mission of the institute (now the ADEA/AAL Institute for Teaching and Learning) was to help participants develop teaching skills and tools for professional growth in their institutions. Currently, a total of 174 individuals have graduated from this program. Many of the participants have benefited from scholarships provided by the American Academy of Periodontology Foundation, the American Academy of Pediatric Dentistry, and American Association of Orthodontists. The program has been extremely beneficial, as 99 percent of the participants have indicated that it was a positive or highly positive learning experience. ${ }^{17}$

Another program is the Academic Dental Careers Fellowship Program (ADCFP) developed by ADEA in 2006 with financial support from the American Dental Association Foundation. This fellowship is designed to foster recruitment efforts by encouraging and preparing students to enter academic dentistry. Ten students are selected each year for a year-long fellowship experience focusing on academic dental careers, mentor training, and support programs. The goals of this fellowship are as follows:

a. training, mentorship, and hands-on experiences in research, teaching, and other aspects of an academic career in dental schools;

b. providing information and perspectives that will assist fellows in making informed choices about dental careers including options for academic careers;

c. creating a cadre of dental school faculty members with the skills to function as academic career mentors for future fellows and other dental students; these would then serve as role models for research and teaching;

d. providing fellows with opportunities to network with dental school administrators and faculty members; and

e. evaluating the effectiveness of the fellowship by collecting data to measure the primary and secondary outcomes.

Outcome measures include information about the percentage of fellows who join dental school faculties within five years of their graduation and the percentage of student participants at academic career seminars who join dental school faculties within five years of their graduation. Currently, thirty-one students have completed the ADCFP, and seven were accepted for the program that began in 2010. All of the thirty-one students who have completed the fellowship have since enrolled in specialty training programs. These students express a continuing interest in an academic career, although in a part-time rather than a full-time role. The students report that their financial debt is the main reason for preferring a part-time role. ${ }^{18}$

Finally, an innovative National Educator Curriculum in Teaching program has been proposed. This program is to be developed and administered through ADEA and will be directed towards all potential faculty members new to education from the sources listed above, regardless of teaching experience, age, specialty education, or clinical experience..$^{19}$ In the long run, this program could be very beneficial in dealing with faculty shortages.

While organizations like ADEA have directed significant efforts toward addressing the issue of faculty shortages, it is important that the preparation of dental students for academic careers start early in their dental education. Developing programs 
within dental schools along with exposing students to these fellowship opportunities has the potential to stimulate interest in an academic career. Schools can identify students interested in becoming future educators and help them realize their potential in this area. Indeed, this program can be extended to the development of guidelines for admissions committees to evaluate some of the candidates on the basis of their past experiences and their potential future role as educators. It has been suggested that selecting a group of dental students with master's degrees or Ph.D.'s might increase the likelihood that they would consider academic careers. Academic development programs can offer students real-time experience by having them teach in didactic courses and preclinical courses as well as some clinical teaching opportunities. Students can mentor underclassmen and even get involved in the admissions process, exposing them to a more global view of how dental schools function. These programs will help students learn through on-the-job training, instilling self-awareness and developing professionalism. This can be very beneficial for the student but also for the institution as a whole in allowing current faculty members to be more effective, build a sense of community, and eventually grow their own faculty ${ }^{14}$ for the future.

We represent significant diversity in terms of background as well as seniority and are associated with seven different dental schools. We have called our model the "Growing Our Own" plan. While not a new idea, we propose to expand on it with a focused and sustained plan across all years of dental training. We also contend that the development of mentoring programs in conjunction with this plan has the potential for greater success than the current existing programs that have met with varied outcomes. Following is a review of the programs at each of our seven dental schools.

Tufts University School of Dental Medicine began an academic development program with one participant from the class of 2001. This was followed by a steady rise over the next nine years, with sixty participants in the class of 2009. Mentoring between faculty and students as well as between students has been emphasized. Responses to a survey conducted after eight years did not result in meaningful outcomes assessments due to a low response rate. Currently, a handful of these students have come back to teach at Tufts, primarily in a part-time capacity. In addition, many of these students have entered postdoctoral programs, creating additional delays in determining the success of the teaching assistance program. Future outcomes assessment measures will be necessary to help evaluate the success of this program.

New York University College of Dentistry has a tutorial program in which predoctoral students become paid tutors, thereby exposing them to some aspects of academic life. The college includes in its core curriculum lectures on dentistry as a profession and as a career. This is also extended to postdoctoral students who take a course on pedagogy and teach up to 10 percent of their total program time.

The University of Texas Health Science Center at San Antonio Dental School currently has a program that allows dental students to graduate with Distinction in Dental Education. This elective program provides the basic skills necessary to be an effective educator while encouraging students to consider a career in dental education. The program extends across the four years of dental school, including didactic coursework in pedagogy and presentation skills as students engage with faculty members to better understand the role of a dental academician. Upon completion, the students complete a project relevant to dental education and present their work to a group of students and faculty members.

The University of Kentucky College of Dentistry recently developed a one-year academic health career fellowship for selected dental students modeled after ADEA's year-long fellowship for teaching and learning. While the ADEA program helps new faculty members who have been in private practice develop teaching skills, the University of Kentucky's fellowship encourages and prepares students to enter academic dentistry. The one-year fellowship, which is aimed at identifying students interested in pursuing academic careers, partners students with academic mentors and provides the student with hands-on experience in research, teaching, and other aspects of an academic career.

Supported by ADEA and the W.K. Kellogg Foundation, the University of Michigan School of Dentistry developed a program geared toward developing students from low-income backgrounds and recruiting faculty from among underrepresented minorities. Features of the program include engaging predoctoral students as early as the first year in faculty development, mentoring families, creation of educational portfolios, educational seminars, community-based opportunities, academic partnerships with other campus entities, and fellowships for 
advanced training. In addition, support for faculty development and loan repayment are essential components of the plan.

The University of Detroit Mercy School of Dentistry recently initiated a monthly Workshop in Academic Dentistry program to introduce dental and dental hygiene students to dental education. Students and faculty members meet for discussions on what is expected of an academic dentist including leadership, pedagogy, and balancing work and family life.

At the Indiana University School of Dentistry, a plan was implemented in 2008 that drew on the concept of developing role models and mentors who worked with the students. These faculty mentors made presentations explaining why they chose their careers in academic dentistry. These presentations also dealt with career choices in dental public health, dental research, and specialization. Other presentations have included information on the financial realities of an academic career, along with help in identifying potential scholarships and available loan repayment plans. In addition, students have been given opportunities to develop their teaching skills while they are in dental school. Currently, there is a significant increase in the interest among the students about being involved with an academic career.

These plans are new, institution-specific, and diverse in their offerings. They currently lack significant outcomes data with regards to their effects on faculty recruitment and retention. However, concurrent with implementing programs to develop future faculty members, the simultaneous development of mentoring programs within individual schools is also critical for long-lasting change on the issue of faculty shortages.

\section{Mentoring}

Mentoring has been defined as "a voluntary and reciprocal interpersonal relationship in which an individual with acknowledged expertise shares his or her experience and learning with another usually less experienced person." ${ }^{20}$ The benefits of mentoring are multifold for the mentee, the mentor, the individual academic institutions, and the profession itself. For the mentored junior faculty member, personal and professional development is a benefit that translates into more confident faculty members who are in tune with the overall vision of the institution and their departments. For the mentor, benefits include develop- ing mutually beneficial professional relationships and the potential to create a legacy within institutions. ${ }^{20}$

While the benefits of mentoring are clear, it has been reported that nationally only about one-third ${ }^{21}$ to one-half $\mathrm{f}^{22}$ of dental faculty members indicate receiving any form of mentoring. According to a survey of dental faculty, ${ }^{23}$ structured activities associated with the mentoring of junior faculty members are not available in a majority of schools. Only 25 percent of the faculty members were aware that a mentoring program was available at their school. Among junior faculty members, only 22.7 percent of those at the rank of assistant professor and 18.9 percent of nontenured associate professors indicated there is a formal mentoring program at their institution. Similarly, 20 percent of all faculty members who responded to the survey were aware of an orientation program available for new faculty members. However, 40.4 percent of those at the assistant professor level noted that an orientation program was available for first-year faculty members, suggesting a possible increase in the number of these programs.

Approximately 35 percent of respondents in that study reported that they did not receive any form of professional guidance or mentoring. ${ }^{23}$ Among those who did, approximately 25 percent were dissatisfied with the quality of the mentoring they received. A majority (61 percent) reported that professional assistance was available for teaching. However, only 46 percent of respondents indicated that professional assistance was available to enhance research skills. ${ }^{23}$ While a majority of those surveyed said they received annual written performance evaluations and were able to set career growth plans with the department chair, opportunities for professional development were not available. Only one-third of those at the associate or assistant professor levels stated they had dedicated time for professional development. A smaller number of respondents ( 26 percent) indicated that funding support was available for sabbaticals and fellowships. ${ }^{23}$

It is therefore essential that mentoring programs be considered mandatory within dental schools. In many institutions, faculty mentoring tends to take place more informally. For example, chairs or program directors may take it upon themselves to mentor and advise junior faculty members in the process of promotion. While these approaches have met with some success, the development of formal institution-based mentoring programs and the assignment of specific mentors are key components for 
future success. When developing mentoring plans, it is important to recognize that not all faculty members are suitable mentors. It is not enough to randomly pair senior and junior faculty members and expect longterm benefits. An unsatisfactory outcome may result when the assigned mentor and mentee have different goals, expectations, or commitments to the process. When assigning mentors, other concerns have been those of control, generational tensions, personality traits, and jealousy. ${ }^{24,25}$

Another consideration in recruiting effective mentors is the changing academic workforce with an increase in the number of underrepresented minority, female, and international faculty members, who play critical roles at dental schools. Assigning appropriate mentor-mentee teams can be challenging for academic institutions especially as dental faculties become more culturally diverse. International faculty members, especially those not familiar with local teaching protocols, could enter an intimidating environment in which they are expected to serve the role of content experts. Recognition of these challenges is paramount in our ability to nurture and develop this cadre of faculty members. While some of the literature on mentoring referenced here has been drawn from medicine, this is readily applicable to dentistry due to the many similarities.

In developing mentoring plans, we recommend that institutions make a commitment to the following:

1. Providing adequate faculty time for mentoring.

2. Choosing and assigning appropriate mentormentee teams.

3. Requiring regular meetings and follow-ups among the teams and the administration.

4. Involving department chairs in the process.

5. Developing long-range goals for the mentee.

6. Providing feedback and advice regularly to the teams from senior faculty and administration.

7. Considering developing cross-disciplinary mentoring teams on university campuses.

Mentoring is a very powerful tool at every stage of professional development. Good mentoring helps with the retention of faculty members who are considered to be the best and brightest.

While many of these suggestions are not new, we want to emphasize that a sustained effort on the part of dental schools is required in all these areas if lasting change is to result. Although this report has mainly focused on growing our own, other approaches including active recruitment from private practice or the uniformed services should continue.
Faculty members who come from these venues could participate in the ADEA/AAL Institute for Teaching and Learning to develop their teaching skills, and similar programs could be developed for the experienced professional within dental schools. Clearly, these programs will require significant time commitment and resources from the schools as well as professional organizations.

While the concept of growing our faculty and developing mentoring programs should serve as cornerstones to help resolve shortages, individual institutional or national programs should also be developed to improve faculty compensation. Loan and tuition repayment programs, scholarships for the development of junior faculty, research funding, and Graduate Medical Education funding for graduate students to minimize loans are all possible options that should be considered. ${ }^{26}$

\section{Faculty Retention}

The challenges of faculty retention are not very different from those of faculty recruitment. The constant financial challenges that schools face make the costs associated with faculty searches impractical, especially when recruiting international faculty members. In addition, retention helps with faculty calibration. This is especially true in the clinical arena as predoctoral students are commonly frustrated when they receive conflicting treatment planning opinions, which in some instances has a negative impact on patient care.

Among the reasons dental graduates choose an academic career is intellectual curiosity in their chosen profession along with a desire to impart knowledge to others and help advance the profession. However, due to the faculty shortage and work overload, many faculty members lack the time to successfully balance various aspects of their career. Recent articles ${ }^{27,28}$ have emphasized the positive and negative aspects of dental faculty life, which are highlighted in Table 1.

However, with the continuing challenge of faculty recruitment and retention, fewer faculty members are taking on bigger roles by choice but rather out of necessity. This appears to be contributing to some of the dissatisfaction with academic careers. A synopsis of these negative aspects is also highlighted in Table 1. 
Table 1. Positive and negative aspects of academic dental careers

\begin{tabular}{ll} 
Positive Aspects & Negative Aspects \\
\hline - Mentorship and Student Interaction & - Bureaucracy/Administrative Burdens and Barriers \\
- Opportunities for Scholarship & - Time Commitment \\
- Jeadership & - Financial Frustration \\
- Intellectual Challenge & - Political Frustration \\
- Satisfaction with Academic Work & - Lack of Mentorship \\
- Lifestyle/Family Compatibility & - Required Research Emphasis \\
- Flexibility/Freedom/Creativity & - Lack of Teaching Skills Development \\
- Lifelong Learning & - Lack of Student Engagement \\
- Befessional Duty & - Imbalanced Workloads \\
- Research Lab Responsibility & - Isolation \\
\hline
\end{tabular}

Sources: Froeschle ML, Sinkford JC. Full-time dental faculty perceptions of satisfaction with the academic work environment. J Dent Educ 2009;73(10):1153-70; Roger JM, Wehmeyer MMH, Milliner BA. Reflections on academic careers by current dental school faculty. J Dent Educ 2008;72(4):448-57.

These positive and negative aspects of an academic dental career reveal the challenges facing dental school administrators. In our opinion, schools would be wise to make a serious effort in the following three areas:

1. Changing the institution's culture. It is important that students view faculty members with respect and see the profession of dental education as noble. A full-time career in dental education should be regarded as a separate and different profession from the full-time clinical practice of dentistry. It is important to change the popular misconception of "those who can, do; those who can't, teach." This should be replaced by "those who can, do; those who can do more, teach." Attracting clinician teachers who are comfortable with both clinical practice and teaching in an academic setting is a key part of this process. Positive role models who demonstrate enthusiasm and passion for their careers in academia as well as clinical practice should be sought after and encouraged to develop within academic institutions.

2. Development of mentoring programs. Developing educators who have or are encouraged to acquire the necessary skills for both clinical and didactic teaching will go a long way in faculty retention. Dental administrators should make a special effort to have mentoring programs in place in their schools as well as within individual departments. Chairs and others who participate in these programs as mentors should be singled out for special recognition by administrators.
3. Adjusting faculty salaries. It has been reported that private practice general dentists earn $\$ 86,000$ a year more than dental school faculty members who are general dentists. This difference is $\$ 170,000$ for specialists and their academic counterparts. These numbers are expected to increase to $\$ 278,000$ and $\$ 454,000$ respectively by $2015 .{ }^{29,30}$ Economic realities and limited institutional budgets may not make it possible for institutions to significantly raise faculty salaries. However, financial incentives can be put in place to narrow the salary discrepancies. These can be addressed by considering increased practice time for the clinicians, consulting or outside lecturing opportunities, and research incentives, in addition to loan repayment programs, scholarships, and tuition waivers for advanced standing programs.

\section{Conclusions}

While dental faculty shortages, especially among clinical faculty, have been discussed for a long time, the complexity of the problem is increasing. The dental curriculum has rapidly evolved from the teaching of dentistry as a technical skills profession to a scientific and analytical as well as a technical skills profession. Accordingly, it is critical to ensure that our schools keep up with the demands of students requiring a high-quality education, the public expecting high-quality dental care, and administrators seeking a higher profile for their schools in the mission 
of the parent universities. Addressing the problem of faculty shortage requires immediate solutions as well as long-term innovative development programs. ADEA has been very proactive in developing future faculty members while working with current faculty members through fellowships and other programs. Dental schools must develop plans to start growing their own faculty. Implementation of programs focused on long-term development of future faculty members within our dental schools including mentoring programs will go a long way to help address and reduce faculty shortages.

\section{Acknowledgments}

The authors would like to acknowledge the help of Prof. Elizabeth Hughes, Clinical Associate Professor, Department of Periodontics and Allied Dental Programs, Indiana University School of Dentistry for her help with editing the manuscript. The authors would also like to acknowledge the assistance of Dr. John Williams, Dean, Indiana University School of Dentistry, and Dr. Karl Haden, President, Academy for Academic Leadership, for their help with the manuscript.

\section{REFERENCES}

1. Kennedy JE. A fifteen-year perspective on dental school faculty. J Dent Educ 1995;59(5):578-83.

2. Haden NK, Weaver RG, Valachovic RW. Meeting the demand for future dental school faculty: trends, challenges and responses. J Dent Educ 2002;66(9):1102-13.

3. Haden NK, Beemsterboer PL, Weaver RG, Valachovic RW. Dental school faculty increase: an update on future dental school faculty. J Dent Educ 2000;64(9):657-73.

4. Hand JS. Identification of competencies for effective dental faculty. J Dent Educ 2006;70(9):937-47.

5. Kennedy JE. The role of tenure and the development of clinical tracks for faculty. J Dent Educ 1981;45(10):663-9.

6. American Dental Education Association. Trends in dental education. Washington, DC: American Dental Education Association, 2006.

7. Okwuje I, Sisson A, Anderson E, Valachovic RW. Dental school vacant budgeted faculty positions, 2007-08. J Dent Educ 2009;73(12):1415-22.

8. Livingston HM, Dellinger TM, Hyde JC, Holder R. The aging and diminishing dental faculty. J Dent Educ 2004;68(3):345-54.

9. Haden NK, Hendricson W, Ranney RR, Vargas A, Cardenas L, Rose W, et al. The quality of dental faculty work-life: report on the 2007 dental school faculty work environment survey. J Dent Educ 2008;72(5):514-31.

10. Guskin AE, Marcy MB. Dealing with the future now: principles for creating a vital campus in a climate of restricted resources. Change, July/August 2003:10-21.
11. Trotman CA, Haden NK, Hendricson W. Does the dental school work environment promote successful academic careers? J Dent Educ 2007;71(6):713-25.

12. Oakley M, Vieira AR. The endangered clinical teacher scholar: will this eliminate discovery from the dental school environment? J Dent Res 2008;87(3):200-2.

13. Chmar JE, Weaver RG, Valachovic RW. Dental school vacant budgeted faculty positions, academic years 2005-06 and 2006-07. J Dent Educ 2008;72(3):370-85.

14. Bertolami CN. Creating the dental school faculty of the future: a guide for the perplexed. J Dent Educ 2007;71(10):1267-80.

15. Chmar JE, Harlow AH, Weaver RG, Valachovic RW. Annual ADEA survey of dental school seniors, 2006 graduating class. J Dent Educ 2007;71(9):1228-53.

16. Rupp JK, Jones DL, Seale NS. Dental students' knowledge about careers in academic dentistry. J Dent Educ 2006;70(10):1051-60.

17. Haden NK, Hendricson WD, Killip JW, O’Neill PN, Reed MJ, Weinstein G, et al. Developing dental faculty for the future: ADEA/AAL Institute for Teaching and Learning, 2006-09. J Dent Educ 2009;73(11):1320-35.

18. Personal communication, Dr. David Brunson, American Dental Education Association.

19. Personal communication, Dr. John Williams, Dean, School of Dentistry, Indiana University.

20. Friedman PK, Arena C, Atchison K, Beemsterboer PL, Farsai P, Giusti JB, et al. Report of the ADEA president's commission on mentoring. J Dent Educ 2004;68(3):390-6.

21. Ramanan R, Phillips R, Davis RB, Silen W, Reede J. Mentoring in medicine: keys to satisfaction. Am J Med 2002;112:336-41.

22. Palepu A, Friedman RH, Barnett RC, Carr PL, Ash AS, Szalacha L, et al. Junior faculty members' mentoring relationships and their professional development in U.S. medical schools. Acad Med 1998;73:318-23.

23. Personal communication on unpublished data from the dental school work-environment survey, Dr. N. Karl Haden, Academy for Academic Leadership.

24. Greene MT, Puetzer M. The value of mentoring: a strategic approach to retention and recruitment. J Nurs Care Qual 2002;17:63-70.

25. Freeman R. Faculty mentoring programs. Med Educ 2000;34:507-8.

26. American Dental Association. 1995/96 survey of predoctoral dental educational institutions: faculty and support, volume 3. Chicago: American Dental Association, 1996.

27. Froeschle ML, Sinkford JC. Full-time dental faculty perceptions of satisfaction with the academic work environment. J Dent Educ 2009;73(10):1153-70.

28. Rogér JM, Wehmeyer MMH, Milliner MS. Reflections on academic careers by current dental school faculty. J Dent Educ 2008;72(4):448-57.

29. Bailit HL, Beazoglou TJ, Formicola AJ, Tedesco L, Brown LJ, Weaver RG. U.S. state-supported dental schools: financial projections and implications. J Dent Educ 2006;70(3):246-57.

30. Walker MP, Duley SI, Beach MM, Deem L, Pileggi R, Samet N, et al. Dental education economics: challenges and innovative strategies. J Dent Educ 2008;72(12): 1440-9. 